\section{The DAEDALUS project, developing institutional repositories at Glasgow University: the story so far}

\author{
Susan Ashworth \\ Morag Mackie and \\ William $\mathcal{F}$. Nixon
}

\section{The authors}

Susan Ashworth is Faculty Support Team Leader, Morag Mackie is Project Manager of the DAEDALUS Project and William J. Nixon is Deputy Head of IT Services, all at Glasgow University, Glasgow, UK.

\section{Keywords}

Archiving, Publishing, Internet, Digital libraries

\section{Abstract}

The DAEDALUS project is funded under the Joint Information Systems Committee, Focus on Access to Institutional Resources Programme for three years until June 2005. The project is based at the University of Glasgow and is developing online institutional repositories for the university, while at the same time encouraging debate and discussion about scholarly communications issues and is made up of two complementary strands: advocacy and service development. This paper sets out the achievements of the project to date and details some of the advocacy strategies that have been used to engage academic staff and researchers with the aims and objectives of the project. Also discussed are some of the barriers which have been faced in obtaining content for the repositories.

\section{Electronic access}

The Emerald Research Register for this journal is available at

www.emeraldinsight.com/researchregister

The current issue and full text archive of this journal is available at

www.emeraldinsight.com/0024-2535.htm

\section{Institutional repositories}

DAEDALUS is one of a number of projects established within higher education institutions throughout the world, which seek to open up access to the published and unpublished research findings of researchers within those institutions. The reasons for this global move towards open access have been well documented (Prosser, 2003) by, among others, SPARC (Scholarly Publishing and Academic Resources Coalition) and its European counterpart (SPARC, Europe, www.sparcurope. org), and in the UK, notably by CURL

(Consortium of University Research Libraries, www.curl.ac.uk/projects/Sherpa.html). Broadly speaking, journal inflation over a number of years has led to severe pressure on most university library budgets, with year-on-year cancellations of journal holdings in these institutions becoming the norm. This has shrunk the pool of research publications available to users, and led to calls for publicly funded research in particular to be made available by researchers freely and openly to anyone who wishes to read it.

One means of making research more accessible is through the creation of institutional repositories, or digital collections of an institution's research output. Not only do repositories make this research freely available, they also provide a showcase for the research output of an individual university, and the open availability of research has tended to significantly increase the impact of that research (Lawrence, 2001).

JISC (Joint Information Systems Committee) established the FAIR (Focus on Access to Institutional Resources) programme, available at: www.jisc.ac.uk/index.cfm?name = programme_ fair) Programme to fund a number of initiatives throughout the UK which include projects to set up a range of institutional repositories in researchled universities. The DAEDALUS Project is one of the projects funded by the JISC FAIR programme. It is also a partner in the SHERPA (Securing a Hybrid Environment for Research Preservation and Access, available at: www.sherpa.ac.uk) Project led by the University of Nottingham.

\section{Service development}

At Glasgow University three repositories have been created for different types of content using different pieces of open source software.

Received 4 March 2004

Reviewed 5 March 2004

Revised 7 March 2004

Accepted 8 March 2004 
The DAEDALUS project

Susan Ashworth, Morag Mackie and William L. Nixon

The EPrints.org software has been used to develop a repository for published and peerreviewed papers (available at http://eprints.gla.ac. uk). Academics were keen that research material of this nature was not made available alongside working papers and content of a less scholarly nature, and therefore the decision was taken to disaggregrate collections, rather than to create a single "super"-repository (Figure 1).

Many departments are keen to find ways of organising and exposing material such as departmental working papers, technical reports, pre-prints and other grey literature. The DSpace software is being used to develop a repository for this type of material (available at: https:// dspace.gla.ac.uk). The software is particularly adaptable, through administration features which allow the task of adding content to be devolved to departments. The content being added to DSpace is of a different nature to already published and peer-reviewed articles and some departments have expressed concern about how decisions about the deposit of this kind of material can be made. Staff such as departmental information officers may be best placed to review and to arbitrate the content to be added to such repositories (Figure 2).

The third repository we have developed is for electronic theses. Staff and students have
Library Review

Volume $53 \cdot$ Number $5 \cdot 2004 \cdot 259-264$

expressed a great deal of interest in making theses more widely available than the current model of print copies accessible only in the physical library building. Since almost all students produce their theses in electronic form, electronic deposit seems a natural extension to the current process.

However, clear guidelines for the deposit of this kind of material, including the possibility of placing embargos on parts of theses, if required by the author, are necessary. The project has been working with relevant university staff to establish the necessary procedures which will allow students to submit an electronic copy of their thesis, initially in addition to a printed copy, in order to fulfil the regulations governing the submission of theses.

Using different software to create the repositories has enabled comparisons to be drawn and recommendations to be made to the open access community. In line with the open access movement each of the packages is freely available and is OAI (Open Archives Initiative) compliant. This means that the repositories can be searched by harvesters such as OAIster (available at: www.oaister.org). The project has published a discussion of some of the software issues (Nixon, 2003) (Figure 3).

One of the major strategic shifts of the project is the decision to move away from encouraging

Figure 1

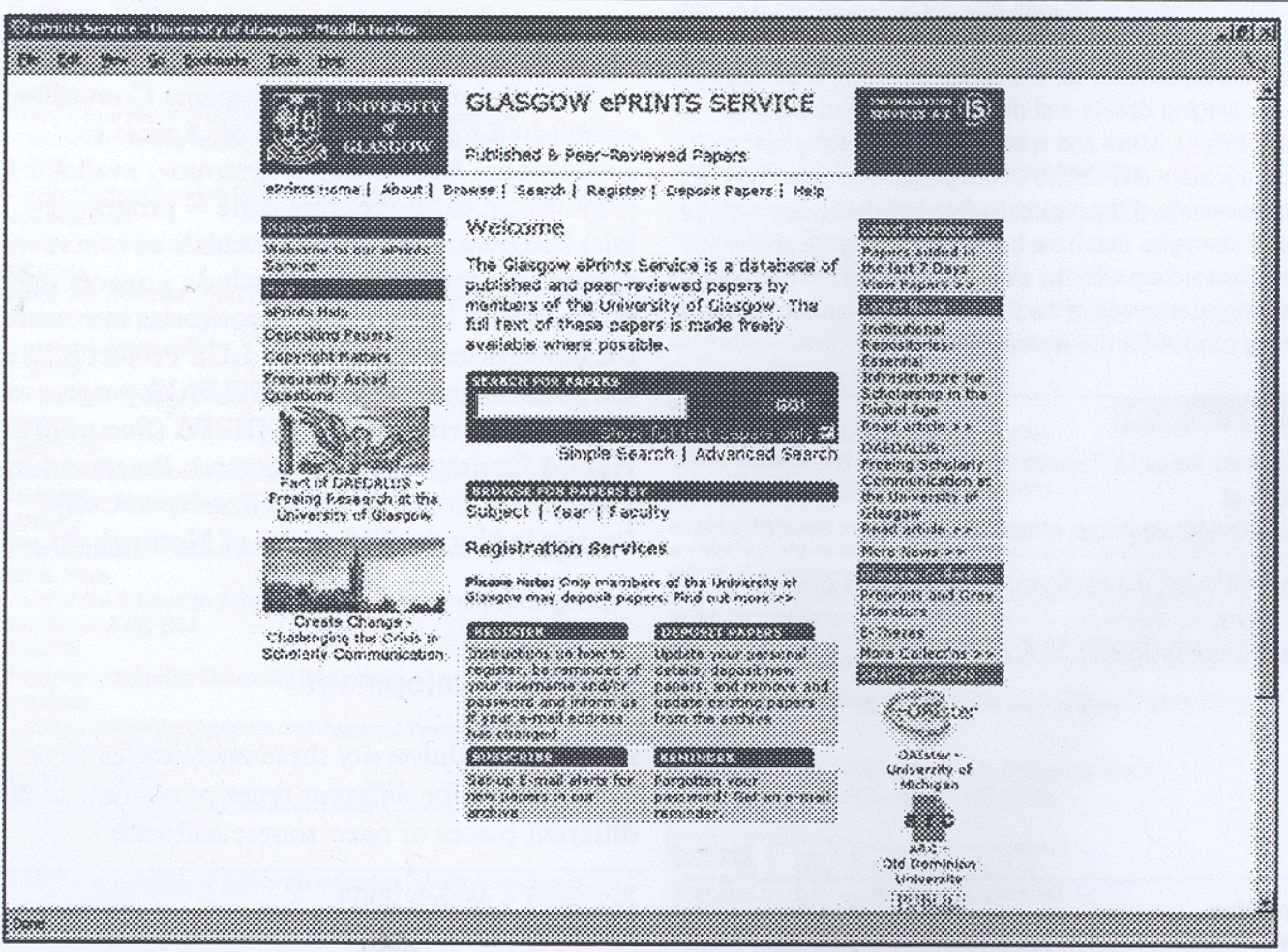




\section{Figure 2}

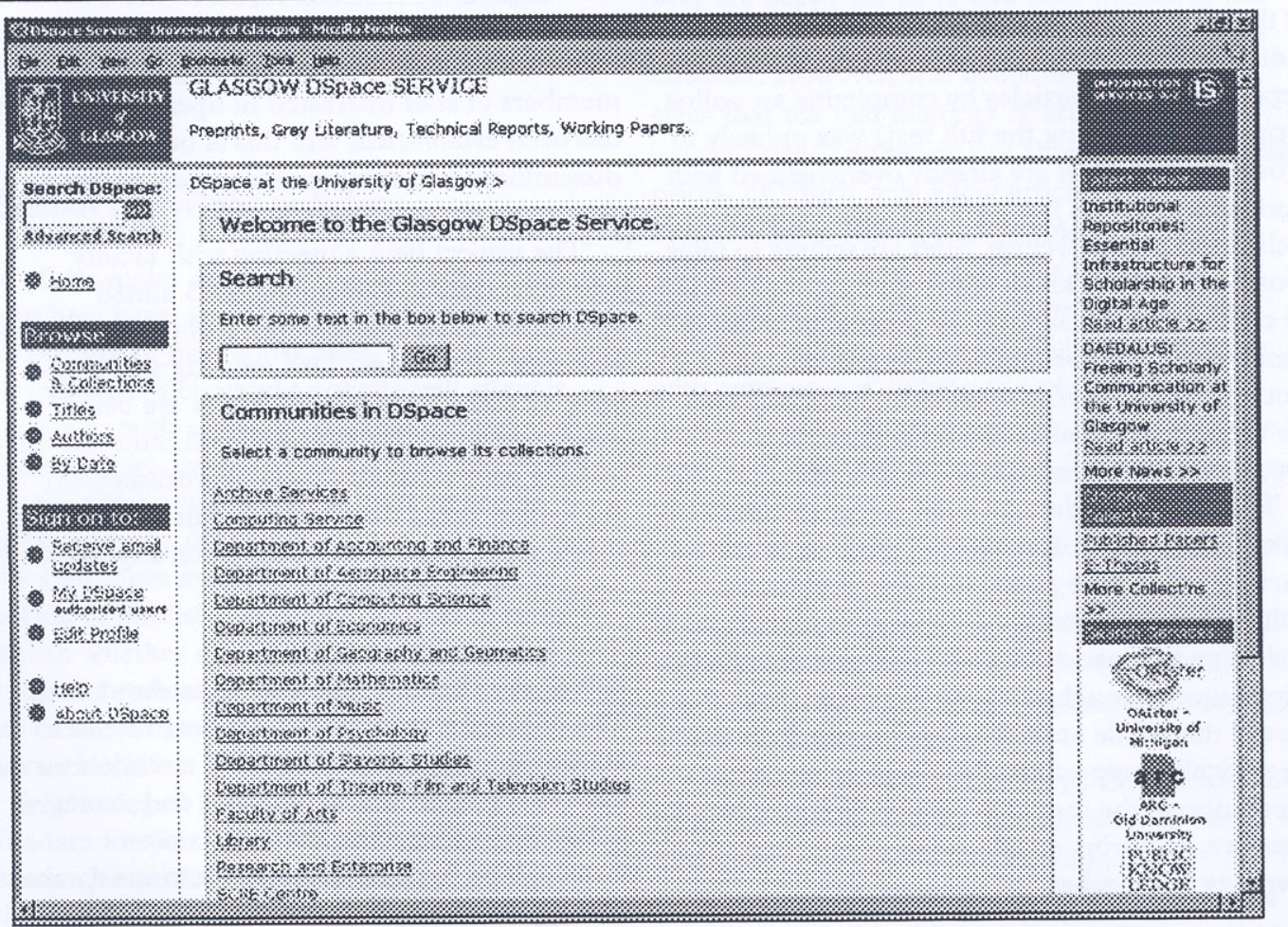

\section{Figure 3}

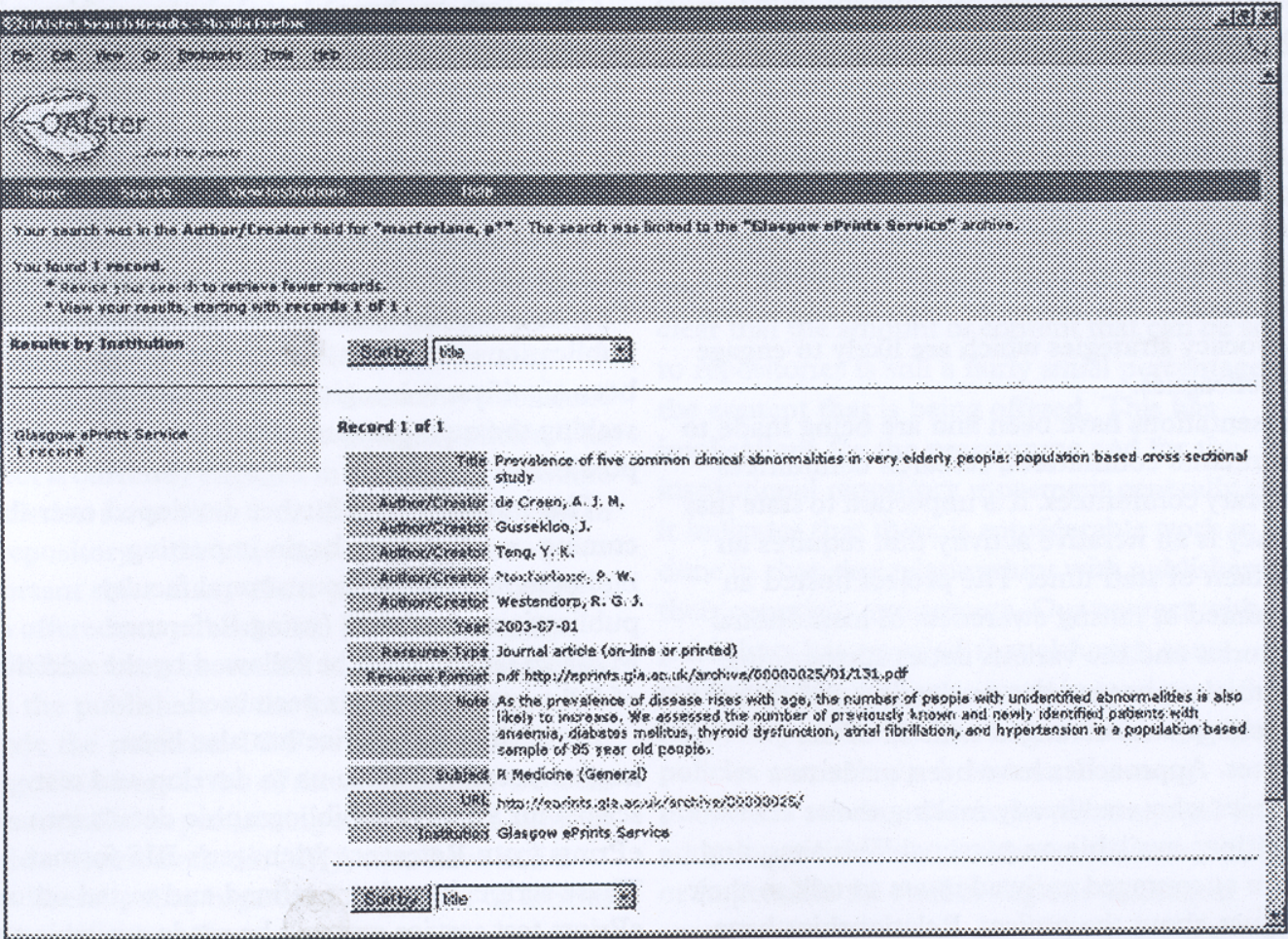


academics to self-archive content, to the provision of a fully mediated service (particularly in the case of the ePrints repository). Early experiences indicated that asking academics to self-archive (i.e. deposit their own articles by completing an online form and submitting the full text) was unlikely to prove popular. Staff are already overwhelmed with work and many do not have the time or the inclination to self-archive. Staff are willing to offer content once they know that copyright issues will be checked for them, and the process of creating metadata and depositing full text will be done for them by project staff. In addition, as library staff are already skilled at metadata creation it is appropriate for them to take on this role.

The need to undertake submission on behalf of stakeholders and academic staff has been a critical learning experience and one which has shaped the technical and advocacy strategies of both the ePrints and DSpace services at Glasgow university. Experience, through advocacy activities, has proved that while academics and researchers are theoretically supportive of the project, the actual population of the service is more difficult and staff intensive, requiring a wide range of ongoing advocacy approaches.

\section{Advocacy strategies: gathering content}

A variety of strategies have been adopted to persuade academics to deposit content in the repositories. Three senior academics from the University's territorial research areas, Physical Sciences, Biological Sciences and Art and Social Sciences, were approached to become members of the project board. These academics have helped enormously in the promulgation of the project's aims and helped us to develop relationships with departments. They have also been able to advise on advocacy strategies which are likely to engage their colleagues.

Presentations have been and are being made to departmental committees, research committees and library committees. It is important to state that advocacy is an iterative activity that requires an investment of staff time. The project hosted an event aimed at raising awareness of institutional repositories and the various issues surrounding their creation, targeted at academics, and followup meetings were arranged with all of the attendees. Approaches have been made to academics who are already making their publications available on personal Web sites, and we have encouraged early adopters to talk to their colleagues about the project. Relationships have also been developed as a result of contacts made through the three faculty support teams in the library, who work closely with staff in the departments they support. A mailing list for members of staff interested in open access issues has been established, and this is being used to disseminate information about open access developments.

The project held a meeting with faculty administrators in December 2003 aimed specifically at raising the profile of the institutional repository for theses. This meeting was very positive and as a result guidelines are being developed to enable students to submit theses, initially on a voluntary basis. A workshop for students is being developed to demonstrate the theses service and gain feedback on any issues and concerns they may have.

\section{Advocacy through publications databases}

The imminent approach of the next research assessment exercise has focussed attention on the university's approach to collating and managing publications data. The library has been instrumental in developing publications databases in many faculties using bibliographic software packages, for example Reference Manager. Many senior management staff within the university are interested in using Glasgow University's institutional repositories to create a single publications database for the whole university.

Therefore, we have recently been working with faculties who have established databases. Scripts have been developed to import bibliographic records from Reference Manager databases into the ePrints repository, and we hope that seeding the repository in this way this will provide us with a means to identify content to be added and a basis for approaching researchers to ask for the full-text. The input of library staff into the creation of publications databases (which has in some cases been significant) has given the project grounds for seeking the quid pro quo of full-text, where that is possible.

This model will be further developed over the coming months as we begin importing bibliographic details from several faculty publications databases (using Reference Manager), which will be followed by the addition of full text where this is permitted.

An ePrints test service has also been implemented to enable us to develop and test scripts for importing bibliographic details into ePrints from Reference Manager's RIS format. These scripts have been refined and tested on our ePrints test service and will be made available to 
the wider community. Future developments of these scripts may convert Reference Manager records into XML (this will be a feature of Reference Manager 11).

\section{Publisher copyright policies}

One of the major concerns that academics and researchers have, when approached to deposit their content in our repositories, is whether or not their publisher's copyright policies will allow it. Discussions with academic staff have revealed that frequently they are not aware of what rights they are signing away when they submit an article to a journal, and one of the aims of the project is to make staff more aware of copyright issues. The checking of publisher copyright polices in order to establish whether or not articles can be added to the repository has become a central part of the work of the project. A useful resource for information about publishers' copyright policies is the list developed by the RoMEO (Rights MEtadata for Open archiving, available at: www.sherpa.ac.uk/romeo.php) Project and now maintained by the SHERPA Project. Although many publishers put information about their copyright polices on their Web sites, it has also been necessary to contact some publishers directly and we have entered into correspondence with a number of publishers worldwide.

Generally, we have asked for permission to add specific articles to the repository and we have also asked for a clarification of publishers' general policies in the area of institutional repositories. We have been pleasantly surprised at the response, particularly from smaller publishers who are often happy to give permission provided that we include a full bibliographic citation. Where publishers have proved to be unaware of the issues we have pointed them towards the RoMEO/SHERPA list in an effort to raise their awareness that many publishers are developing more flexible copyright policies. The project is currently engaged in attempting to secure permission for articles from Elsevier to be added to the repository - the outcome of this will be important since many of the papers which we have been offered are published in Elsevier journals.

We have been successful in gaining permission from the publishers of the journal Nature to include the publisher PDF version of articles by Glasgow authors in the ePrints repository. We were also successful in persuading academics to allow us to add content from the $B M \mathcal{F}$, who have had a more liberal policy regarding the re-use of articles they publish since January 2000.
A growing number of staff are indicating that they are happy for us to add their papers to the repository so long as copyright implications are checked. However, it is becoming increasingly clear that the vast majority of articles are from journals which either do not allow deposit of postprints, or which only allow articles to be made available on personal or departmental sites. Although we intend to pursue a number of strategies to increase our content, we may also have to consider alternative methods of dealing with content, e.g. linking to articles on staff personal pages, or working with staff to produce a version of their articles which publishers will allow us to deposit.

As a result of our contact with publishers we are now pursuing a policy of letting staff know the outcomes of our negotiations with publishers. This will raise awareness of the need for staff to consider more carefully the copyright agreements they sign when submitting articles.

The feedback and work with publishers has also been fed into the service development of the ePrints repository to accommodate the requirements of publishers in making postprints available, with the addition of a number new fields. Publishers' conditions have included a copyright statement and an acknowledgement of where the paper was first published. We have also indicated that we have permission to reproduce the paper (Figure 4).

The decision, as described above, to move from a model of self-archiving to the provision of a fully mediated service has had an impact on the strategies we are employing to gather content, in particular for the ePrints service. Contact with publishers and our experiences in checking copyright agreements for staff have made it very clear that the amount of content that can be added to repositories is still a fairly small percentage of the content that is being offered. This has implications for the programme and for the institutional repository movement generally since it indicates that there is considerable work to be done in changing relationships with publishers and their copyright agreements. Our contact with publishers has revealed that although some publishers are willing to work in tandem with the repository movement and alter their copyright policies accordingly, it is clear that many publishers see repositories as a threat, and are adopting policies which either make it very difficult or impossible for staff to deposit content in repositories. 


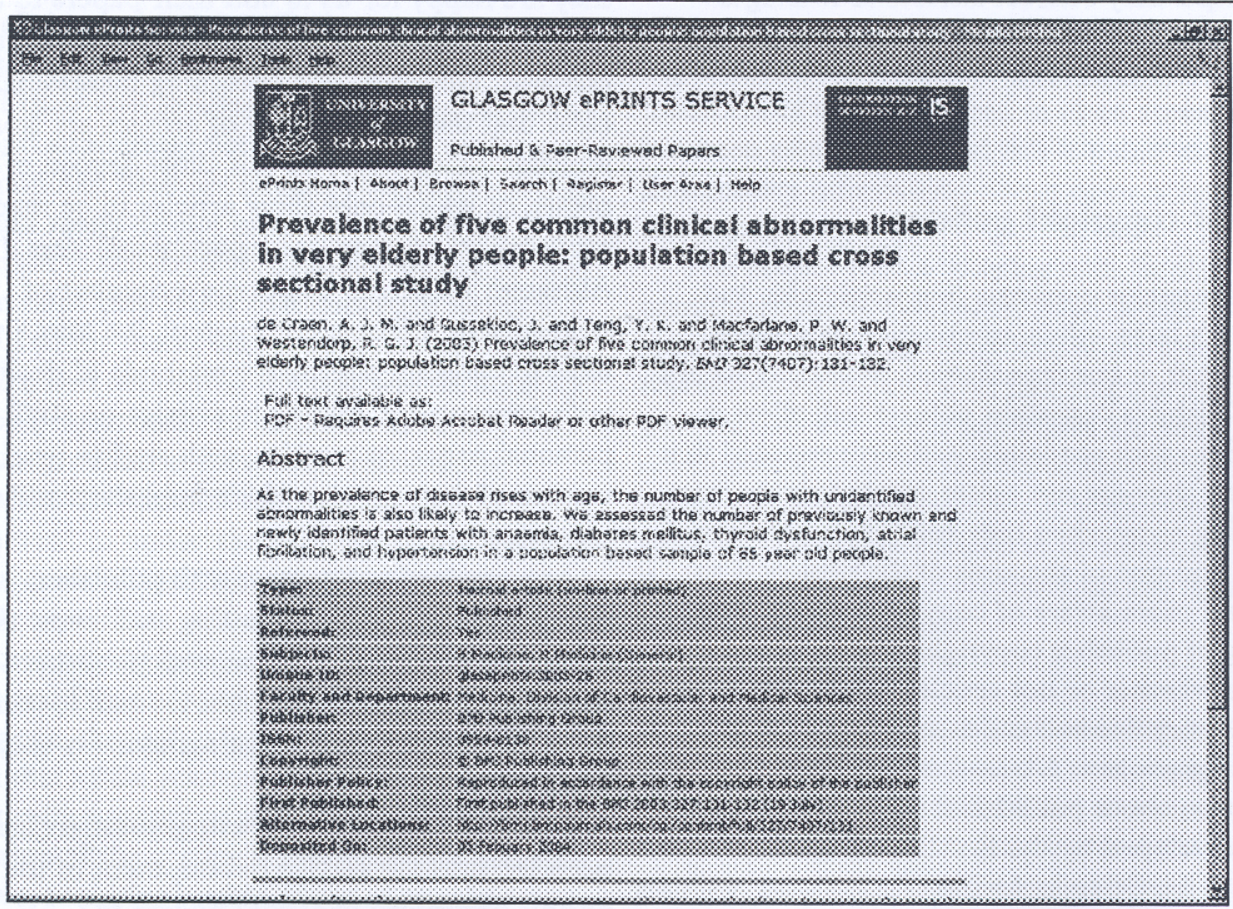

\section{The future}

A major factor in ensuring the long-term success of the institutional repository movement will be the amount of content available and the use of this content. The creation of a large number of institutional repositories through programmes such as FAIR in the UK and the SURF initiative's DARE (Digital Academic Repositories, available at: www.surf.n1/en/themas/index2.php?oid = 7) in The Netherlands is driving the creation of a critical mass of freely available content.

The advocacy activities described in this article are now bearing fruit and will enable us to contribute towards this mass of content. Advocacy and population of the services, however, is only the beginning of the work, our academic colleagues who have provided us with their research will expect it to be available beyond the lifetime of the project. The transition of DAEDALUS from a research project into an integral and embedded institutional service is now being mapped out in the projects exit strategy.

\section{References}

Lawrence, S. (2001), "Free online availability substantially increases a paper's impact", Nature, Vol. 411 No. 6837, p. 521.

Nixon, W.J. (2003), "DAEDALUS: initial experiences with EPrints and DSpace at the University of Glasgow", Ariadne, Vol. 37 October, available at: www.ariadne.ac.uk/issue37/nixon/ (accessed 8 March 2004)

Prosser, D. (2003), "Scholarly communication in the 21 st century - the impact of new technologies and models", Serials, Vol. 16 No. 2, pp. 163-7. 